\title{
FOIL CIRCUITS
}

\author{
K. H. HOUSKA \\ Siemens AG, Unternehmensbereich Bauelemente Folien-Produkte (Werk Kondensatoren), \\ 8000 München 80, Balanstraße 73, Germany (BRD)
}

(Received February 22, 1980)

\begin{abstract}
Progress in integration of passive components is of essential importance for many applications along with the high integration rate of semiconductors. A further asset in view of the integration of passive components, like the field of peripheral circuits, is a new technology on the base of low-cost plastic materials, called Sicufol ${ }^{\circledR}$. With this new technology it is possible to integrate capacitors, coils and NiCr-resistors. Investigations shows that passive components with very good properties can be produced. A summary of climatic tests carried out on NiCr-resistors with $\mathrm{Cu}$-contacts and capacitances are shown. HF-applications and some low frequency applications (e.g. a simple resistor network) show that conventional or hybrid components can be soldered on plastic foils using this technology.
\end{abstract}

\section{INTRODUCTION}

The integration of passive components is usually achieved using thick- or thin-film techniques. These techniques require the use of high quality and therefore costly materials such as borosilicate glass or ceramic for the substrates. The range of applications is thus limited by economic considerations. The purpose of the development of circuits on plastic foils is to widen the field of application to include for instance peripheral circuits for integration.

The first question to be answered was what was the feasibility of producing integrated circuits, with resistor networks on plastic foils which could substitute for those on solid substrates.

The second question was whether it is possible to make the plastic foil carrying the resistors thin enough, that it can be used as a dielectric for capacitors if both sides of the foil are coated with an appropriate pattern. Then through connections and flat coils can also be produced.

\section{TECHNOLOGY}

Figure 1 shows the basic constructions of circuits on plastic foils. Integrated $\mathrm{NiCr}$-resistors and capacitors, with the plastic foils as dielectric are shown. Also there are shown some flat coils and a through connection. The connections and coils are produced by etching the $\mathrm{Cu}$ coating. Connections can be produced through the insulation plastic foils by a

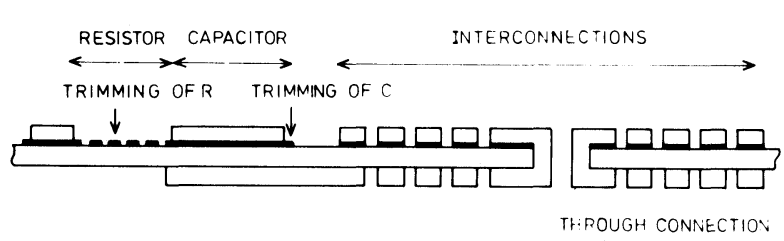

FIGURE 1 Schematic cross-section of an integrated circuit on plastic foil .

variety of methods, thus simplifying the circuit layouts. The trimming of the resistors or capacitors is successfully carried out with a YAG-Laser system. The integrated components can be trimmed directly or through the foil. In the last case it is possible to make a functional adjustment on capsuled integrated circuits.

The laminate is produced at first by vacuum evaporation of the $\mathrm{NiCr}$ film and the copper film on a plastic foil. The films are evaporated in the same vacuum because the interfacial resistance between copper and nichrome must be low and does not change under varying climatic conditions. The evaporation of $\mathrm{NiCr}-\mathrm{Cu}$-films can be performed on both sides of plastic foils. The process of evaporation is similar to the aluminium metallisation on plastic foils for capacitors.

The second step of production is to galvanize with copper the evaporated plastic foil, in several thicknesses, to make the copper film solderable. The thickness is between $5 \mu \mathrm{m}$ to $20 \mu \mathrm{m}$. The thickness of $\mathrm{NiCr}$-film depends on the area resistance and is $100 \mathrm{ohm}$ at $10 \mathrm{~nm}$. 
The following steps are photo-etching processes for making the structure of integrated components on the plastic foil e.g. resistors, capacitors, interconnections, cross-overs and flat coils.

The handling of the structured laminate is very difficult. Therefore the circuit must be stiffened before it is sent to the customer. The material to stiff the laminate may be plastic, hard-paper, or aluminium.

\section{RANGE OF VALUES, TESTS AND CLIMATIC CONDITIONS}

Our investigations showed that it is possible to produce nichrome resistor films, with good properties, on plastic film. Two different conductor/resistor systems on foils were investigated, first the combination $\mathrm{Al} / \mathrm{NiCr}$ and then the $\mathrm{Cu} / \mathrm{NiCr}$ combination. Both systems have advantages and disadvantages and thus the user must select the system most suitable for his application.

In Figure 2 is a table of the stability of resistors using the $\mathrm{Al} / \mathrm{NiCr}$ system. The resistance change under three different climatic conditions is shown. On the abscissa the time to 4000 hours is shown and on the ordinate the relative resistance change is shown. The upper curve represents the stability of resistors under load at an ambient temperature of $+70^{\circ} \mathrm{C}$. The curve beneath it shows the resistance change at $+40^{\circ} \mathrm{C}$ and $93 \%$ rel. humidity, with a small load in order to examine electrolyte corrosion. The third and lowest curve represents the resistance change on storing in an ambient temperature of $125^{\circ} \mathrm{C}$. The mean change of resistance is in all three cases very small and is within $+0.15 \%$ for 4000 hours. The interfacial resistance between aluminium films and nichrome films is low and does not change under varying climatic conditions. The value measured was $0.10 \mathrm{ohm} . \mathrm{mm}$

We also made some climatic tests on NiCr-resistors with $\mathrm{Cu}$ contacts. The interconnections were

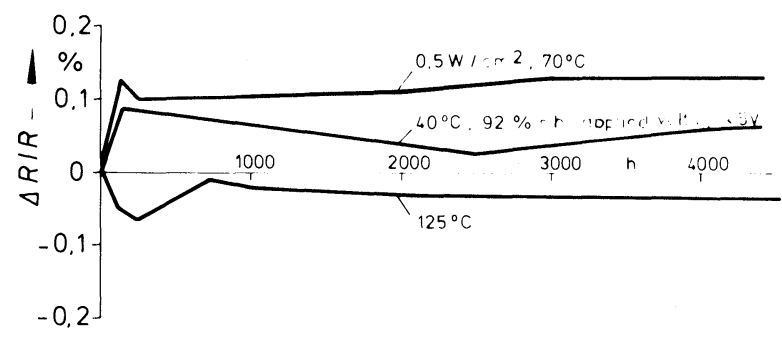

FIGURE 2 Long-term stability of CrNi-films.

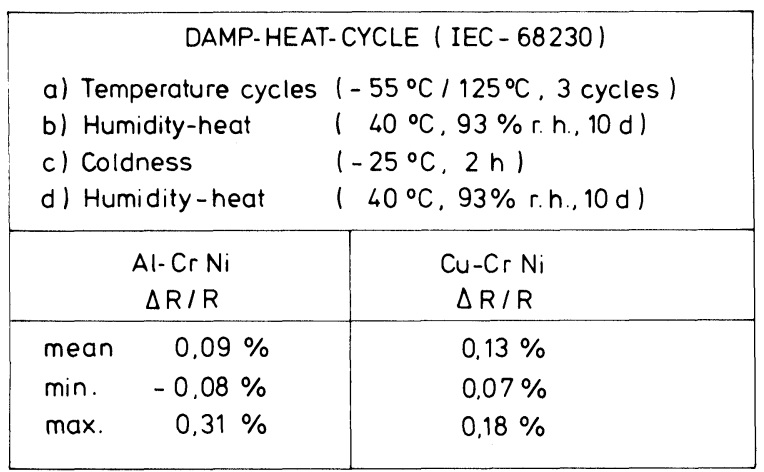

FIGURE 3 Resistors on plastic foil in damp-heat cycle.

produced with thicknesses of up to $20 \mu \mathrm{m}$. The interfacial resistance between $\mathrm{Cu}$ and $\mathrm{NiCr}$-films is also very small and is a little affected by climatic changes as with Al-NiCr-films. Temperature-cycling of resistors in the range $-55^{\circ} \mathrm{C}$ to $+125^{\circ} \mathrm{C}(10$ cycles $)$ produces a mean resistance change of $0.8 \%$.

A resistance change of $0.5 \%$ is obtained after $1000 \mathrm{hrs}$ storage at $+70^{\circ} \mathrm{C}$ under a loading of 0.5 $\mathrm{W} / \mathrm{cm}^{2}$. In comparison $1000 \mathrm{hrs}$ storage at $+40^{\circ} \mathrm{C}$ at $93 \%$ relative humidity produces a resistance change of merely $0.4 \%$.

Figure 3 shows the behaviour of the resistors on being exposed successively to four different climates. This combined climate is called the "Damp-heatcycle" (IEC-68230) and consists of three temperature cycles between $-55^{\circ} \mathrm{C}$ and $+125^{\circ} \mathrm{C}$, a humidity heat test for 10 days in $93 \% \mathrm{r}$. humidity and $40^{\circ} \mathrm{C}$, coldness test for two hours at $-25^{\circ} \mathrm{C}$ and again the humidity heat test at $40^{\circ} \mathrm{C}, 93 \% \mathrm{r}$. humidity for 10 days. The mean value for the $\mathrm{Al}-\mathrm{NiCr}$-system is $0.9 \%$, and for the $\mathrm{Cu}-\mathrm{NiCr}$-system is $0.13 \%$.

$\mathrm{NiCr}$ resistors on plastic foils are stable and show good properties under various test conditions, as shown in Figures 2 and 3, and also for this combined climate. The conductor system, whether $\mathrm{Al}$ or $\mathrm{Cu}$, hardly affects the stability. Figure 4 shows that the temperature coefficient of $\mathrm{NiCr}$ resistors on plastic foils is greatly affected by composition of the film.

On the abscissa the Cr-content and on the ordinate the temperature coefficient is shown. Thus the TCR is lowest, in general less than $10 \mathrm{ppm} / \mathrm{K}$, for films with $53 \% \mathrm{Cr}$. The TCR lies at about $600 \mathrm{ppm} / \mathrm{K}$ for films with $20 \% \mathrm{Cr}$ and $80 \% \mathrm{Ni}$.

It is possible, therefore, to obtain a particular TCR by adjusting the constituent parts of the film. This is necessary to achieve a temperature compensation with capacitors for application, for instance, in high quality filters. 


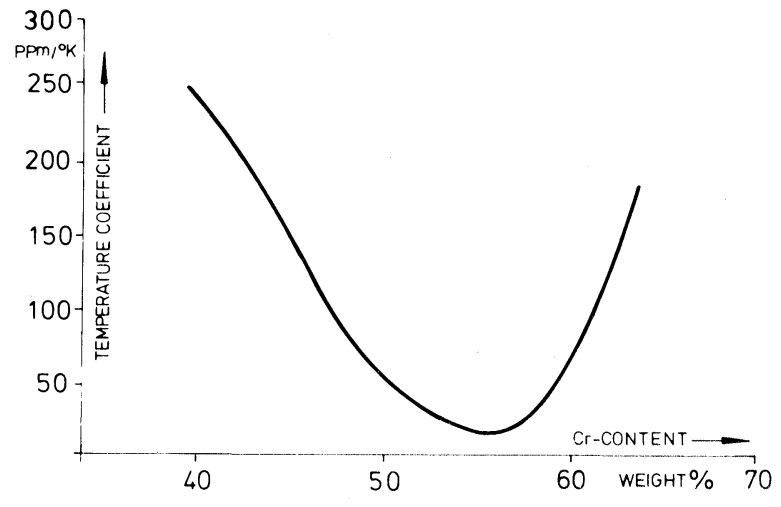

FIGURE 4 Temperature coefficient of evaporated CrNi-films.

If the plastic foil carrying the resistors is thin enough, then it is possible to use it as a dielectric film for capacitors, if both sides of the foil are coated with an appropriate pattern.

Figure 5 lists the parameters for integrated capacitors on polyimid and teflon foils. Mean capacitances of $120 \mathrm{pF} / \mathrm{cm}^{2}$ for PI with the thickness of $25 \mu \mathrm{m}$ and about $150 \mathrm{pF} / \mathrm{cm}^{2}$ for teflon with the thickness of $13 \mu \mathrm{m}$ can typically be achieved. The dissipation factor depends on the foil properties on frequency and on humidity. A value of $6.10^{-4}$ (at $1 \mathrm{MH}_{2}$ ) is obtained with TFE and FEP foils.

These capacitors are also stable on storage at $70^{\circ} \mathrm{C}, 100 \% \mathrm{r}$. humidity for a three-day test. The mean capacitance change for a measurement frequency of $1 \mathrm{MH}_{2}$ is $0.1 \%$. The dissipation factor does not change at $1 \mathrm{kH}_{2}$. The value is $2,1.10^{-3}$. Polyimid foils in dry environments show similar values, although increased humidity leads to changes in the capacitance and dissipation factor.

\begin{tabular}{|c|c|c|c|c|}
\hline & \multicolumn{2}{|c|}{$\begin{array}{c}\text { POLYIMID }(25 \mu \mathrm{m}) \\
\varepsilon=3,5\end{array}$} & \multicolumn{2}{|c|}{$\begin{array}{l}\text { TEFLON }(13 \mu \mathrm{m}) \\
\varepsilon=2.0\end{array}$} \\
\hline Mean Capacitance & \multirow{3}{*}{\multicolumn{2}{|c|}{$\begin{array}{l}117 \mathrm{pF} / \mathrm{cm}^{2} \\
115 \mathrm{pF} / \mathrm{cm}^{2}\end{array}$}} & \multirow{3}{*}{\multicolumn{2}{|c|}{$\begin{array}{l}150 \mathrm{pF} / \mathrm{cm}^{2} \\
148 \mathrm{pF} / \mathrm{cm}^{2}\end{array}$}} \\
\hline $1 \mathrm{kc}$ & & & & \\
\hline $1 \mathrm{mc}$ & & & & \\
\hline dissipation factor & \multirow{4}{*}{\multicolumn{2}{|c|}{$\begin{array}{l}3,4 \cdot 10^{-3} \\
6,5 \cdot 10^{-3} \\
7,8 \cdot 10^{-3}\end{array}$}} & \multirow{4}{*}{\multicolumn{2}{|c|}{$\begin{array}{l}2,1 \cdot 10^{-3} \\
0,6 \cdot 10^{-3}\end{array}$}} \\
\hline $1 \mathrm{kc}$ & & & & \\
\hline $1 \mathrm{mc}$ & & & & \\
\hline $100 \mathrm{mc}$ & & & & \\
\hline humidity & $1 \mathrm{kc}$ & $1 \mathrm{mc}$ & $1 \mathrm{kc}$ & $1 \mathrm{mc}$ \\
\hline $\begin{array}{c}70^{\circ} \mathrm{C} \quad 100 \% \text { r.h. } \Delta \mathrm{C} / \mathrm{C} \\
3 \text { day test } \\
\operatorname{tg} \delta\end{array}$ & $\begin{array}{l}6.9 \% \\
4.1 \cdot 10^{-3}\end{array}$ & $6.8 \%$ & $\mid \begin{array}{l}-0.6 \% \\
2.1 \cdot 10^{-3}\end{array}$ & $0.1 \%$ \\
\hline
\end{tabular}

FIGURE 5 C-integration on plastic foil.

\begin{tabular}{|c|c|}
\hline RESISTORS & \\
\hline $\begin{array}{l}\text { Resistivity } \\
\text { Range } \\
\text { Power } \\
\text { Temp.-Coefficient } \\
\text { Non-linearity } \\
\text { Current noise }\end{array}$ & $\begin{array}{l}20 \Omega / 0 \text { to } 300 \Omega / 0 \\
10 \Omega \text { to } 500 \mathrm{k} \Omega \\
0,5 \mathrm{~W} / \mathrm{cm}^{2} \\
0 \text { to } 600 \mathrm{ppm} /{ }^{\circ} \mathrm{C} \text { (variable) } \\
\text { ca. } 120 \mathrm{~dB} \\
-30 \mathrm{~dB} \text { to }-40 \mathrm{~dB}\end{array}$ \\
\hline CAPACITORS & \\
\hline $\begin{array}{l}\text { Capacitance } \\
\text { Dissipation factor } \\
\text { Breakdown voltage }\end{array}$ & $\begin{array}{l}148.4 \mathrm{pF} / \mathrm{cm}^{2}(1 \mathrm{mc}) \\
0.6 \cdot 10^{-3} \quad(1 \mathrm{mc}) \\
>100 \mathrm{~V} / \mathrm{\mu m}\end{array}$ \\
\hline
\end{tabular}

FIGURE 6 R-C Integration on plastic foil.

Resistors and capacitors on foils can be produced with the range of values as shown in Figure 6. Area resistances of $20 \mathrm{ohm}$ to $300 \mathrm{ohm}$ are possible. Using resistance meandering it is possible to increase these values by a factor of 3800 . The working power dissipation is $0.5 \mathrm{~W} / \mathrm{cm}^{2}$. The TCR can be varied between 0 and $600 \mathrm{ppm} /{ }^{\circ} \mathrm{C}$. The distortion attenuation is about $120 \mathrm{~dB}$ and the noise index is between $-30 \mathrm{~dB}$ and $-40 \mathrm{~dB}$. Values up to 150 $\mathrm{pF} / \mathrm{cm}^{2}$ have been achieved for the capacitors using the carrier foil as dielectric. The capacitors and the dissipation factors are stable under climatic conditions. The break down voltage is higher than $100 \mathrm{~V} / \mu \mathrm{m}$.

At this time we are not able to make resistornetworks on teflon foils, only on polyimid films, because the teflon film has too small a mechanical stability. Therefore each thin metal-film, as $\mathrm{NiCr}$ on teflon (FEP) will be disturbed by any mechanical distortion.

\section{ADVANTAGES}

We find that two factors make this product cheap. First the low cost materials e.g. the price per square metre of polyimid film is 10 to 30 times cheaper than the equivalent ceramic substrate for thick films. Copper and $\mathrm{NiCr}$-films (smaller $100 \mathrm{~nm}$ ) are low cost materials.

Secondly the process of fabrication which is done by continuous band as far as possible, also makes the product cheap.

The technical advantages are that resistors and a great part of the other passive components can be integrated. Cross-overs, flat coils, interconnections capacitors and also resistors are etched out with one photo-etching process of one laminate. The substrate of circuits is flexible, therefore it is possible to make 
flexible interconnections from one circuit to the other.

The integrated components are extremely flat. They facilitate automatic insertion. The $\mathrm{NiCr}-\mathrm{Cu}$ system is solderable. All conventional components can be inserted and soldered in the same way as on printed boards. Hybrid components also can be reflow soldered.

The geometrical dimensions of the integrated components have good reproduceability because we employ a fine photo-etching technique. Therefore the tolerances of integrated resistors can be kept smaller than $\pm 10 \%$, without laser-trimming. Also tolerances of the capacitors are smaller than $\pm 10 \%$ because they only depend on the tolerance of the plastic foil thickness. For HF-applications geometrical constancy of the integrated components is a great advantage in circuit layout and in production.

\section{APPLICATIONS}

Figures 7 to 12 show some applications of Sicufoltechnic.

Figure 7 shows a simple single in line resistor network. Figure 8 shows an antenna amplifier for wide band, inserted with hybrid components. This network

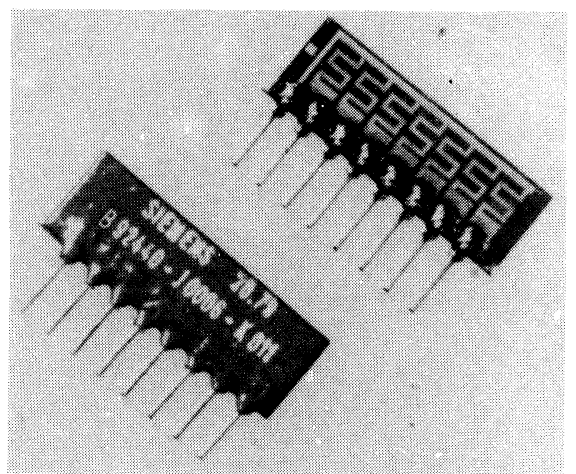

FIGURE 7 SIL-resistor network.

replaces a thin film network of the same size. Figure 9 shows an input-filter (band III) for an antenna amplifier. This filter is fully integrated and consists of five coils and six capacitors.

Figure 10 shows an antenna wall socket with an integrated transformer. All capacitors and coils are integrated without the load-resistor.

Figures 11, 12 show an IF-module with integrated $\mathrm{R}, \mathrm{C}, \mathrm{L}$, and with conventional components inserted. This work has been partially supported by the technological program of the Federal Department Research and Technology of the FRG.

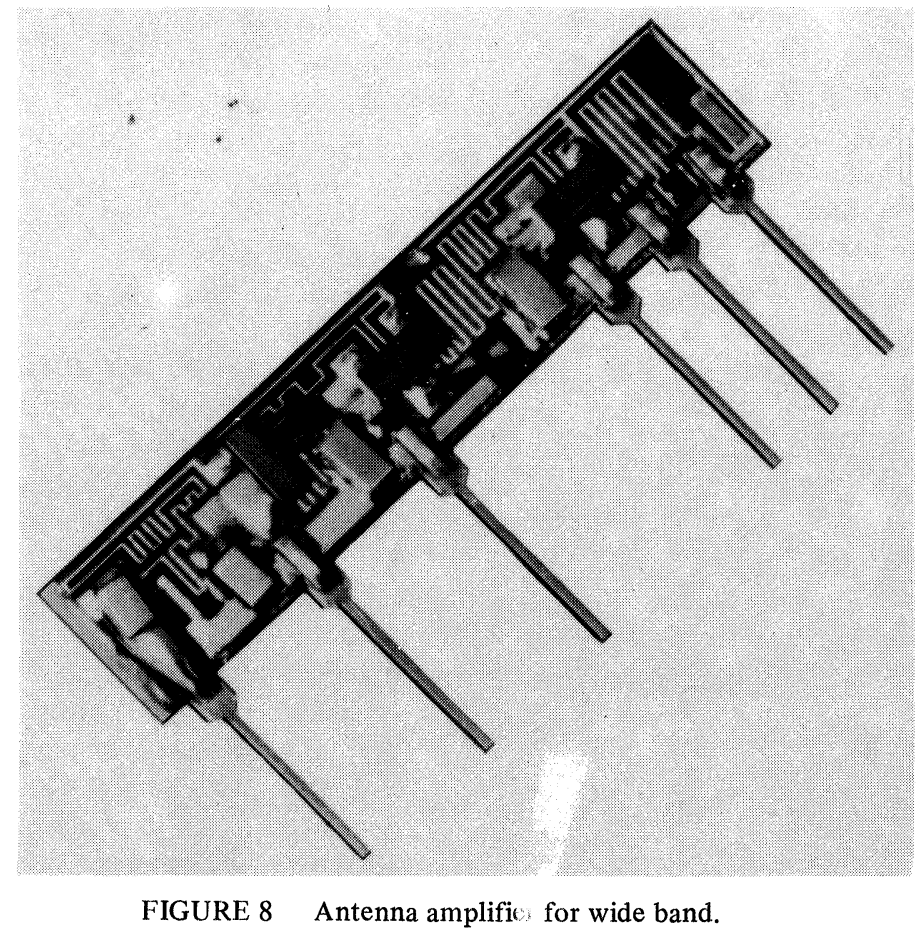




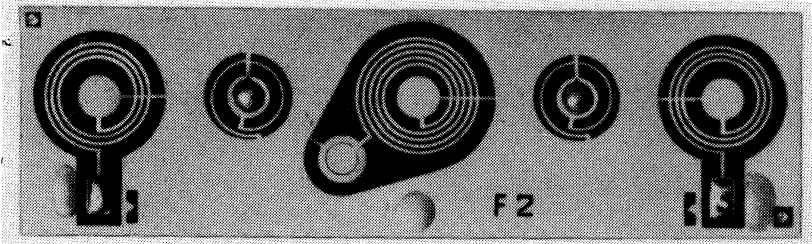

FIGURE 9 Input filter (band III).
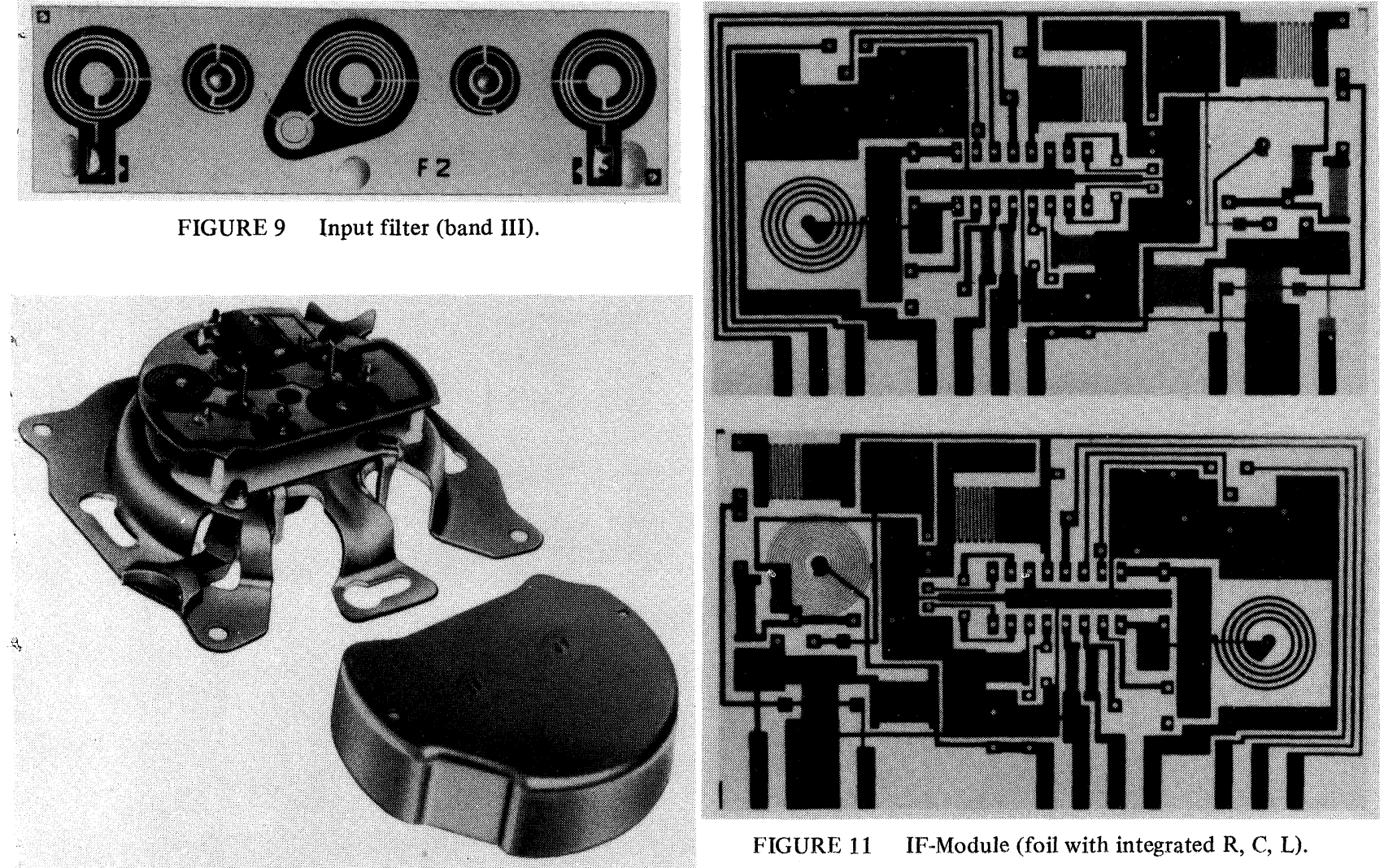

FIGURE 11 IF-Module (foil with integrated R, C, L).

FIGURE 10 Antenna wall-socket with integrated transformer.

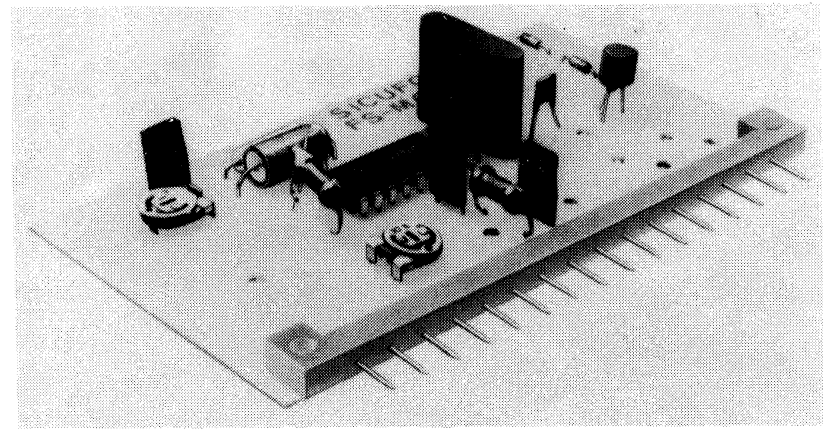

FIGURE 12 IF-Module with conventional components inserted. 

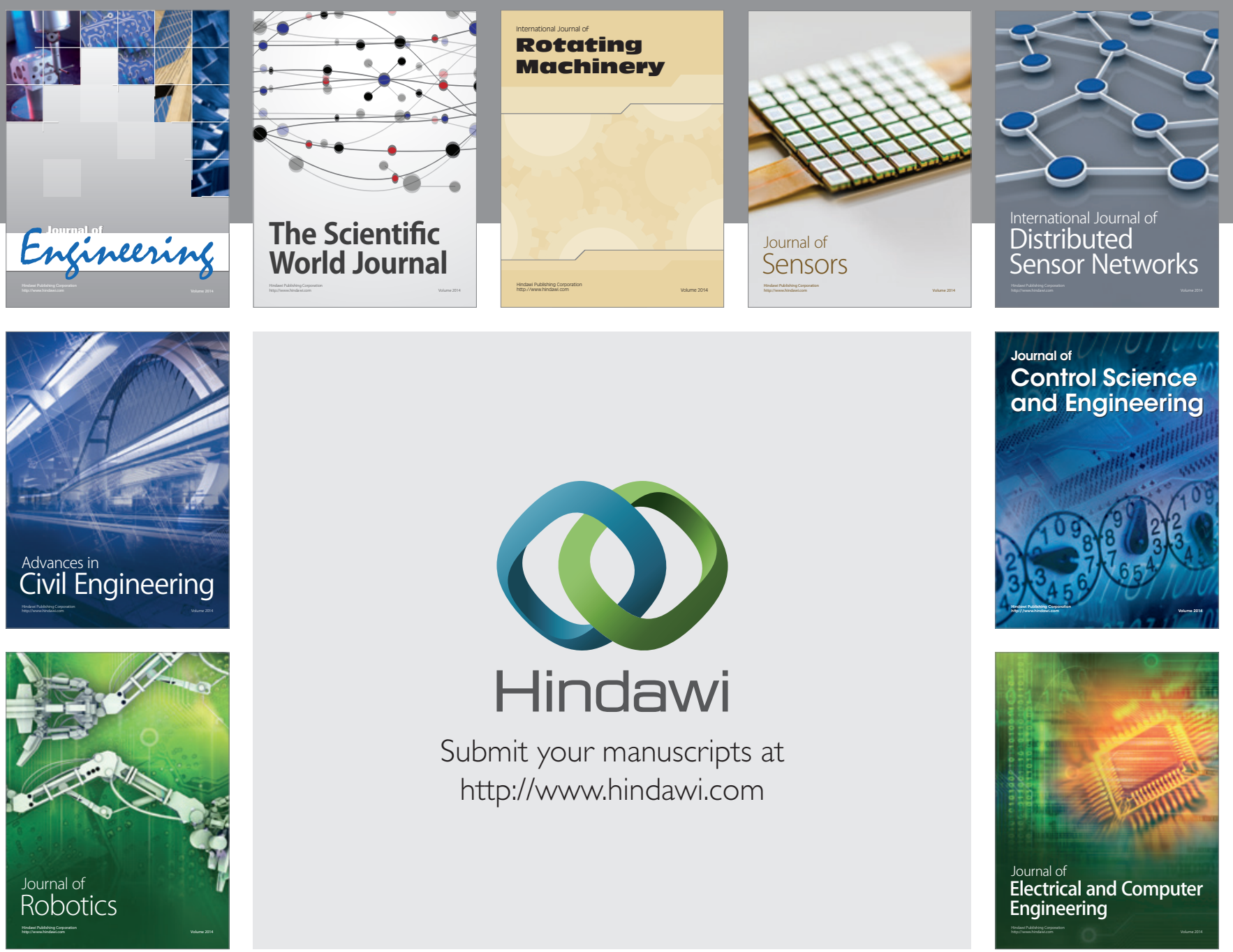

Submit your manuscripts at

http://www.hindawi.com
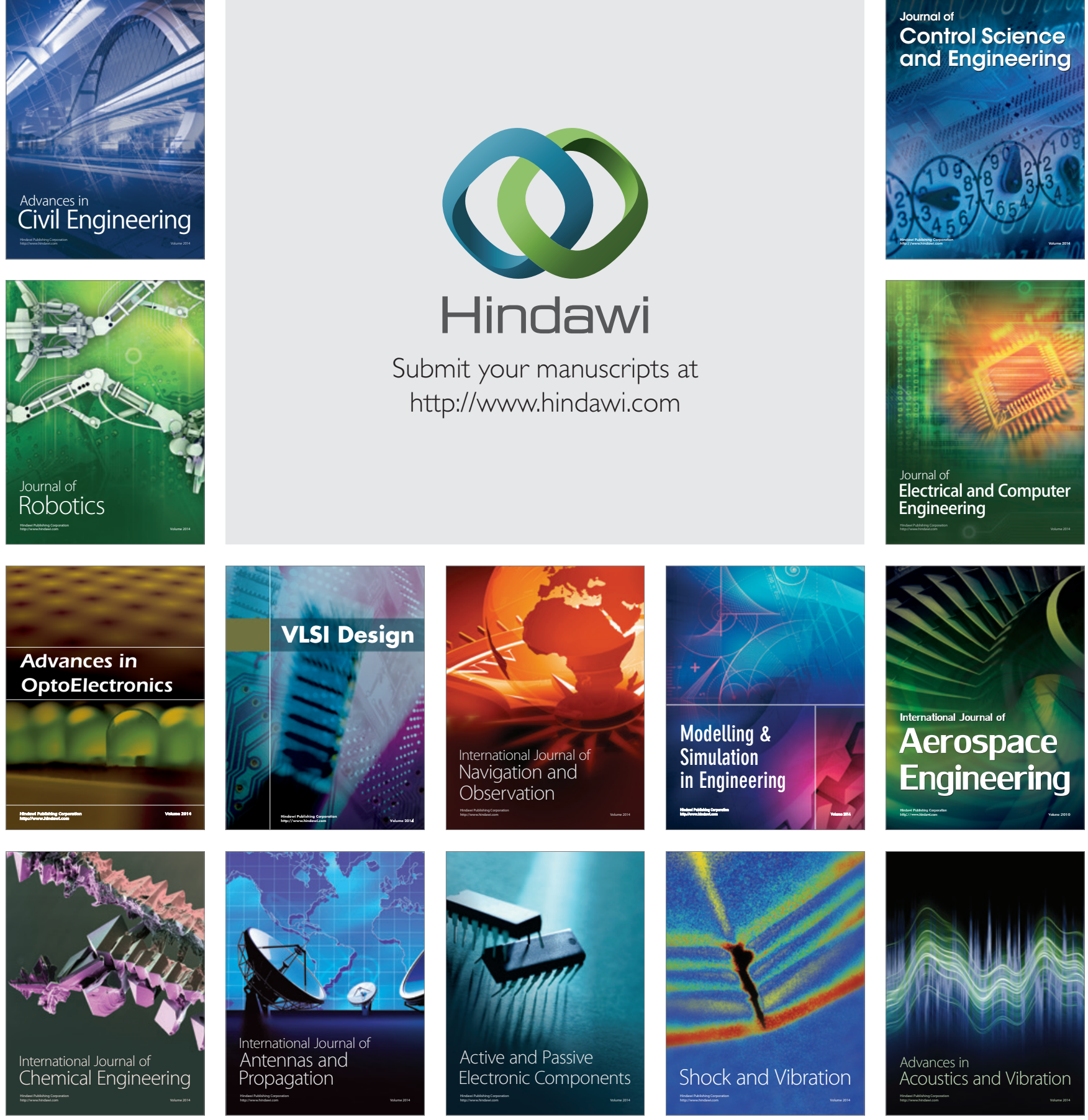